\title{
AS FRAGILIDADES DO ESTADO NA REGULAÇÃO DAS NOVAS TECNOLOGIAS: UMA ANÁLISE DA AUTORREGULAÇÃO NO QUE TANGE AS NANOTECNOLOGIAS
}

\author{
THE FRAGILITIES OF THE STATE WHEN REGULATING NEW TECHNOLOGIES: AN \\ ANALYSIS OF SELF-REGULATION IN THE CONTEXT OF NANOTECHNOLOGIES
}

\section{Cristian Ricardo Wittmann}

\begin{abstract}
Doutor em Direito pela Universidade do Vale do Rio dos Sinos (UNISINOS); Mestre e Graduado em Direito pela Universidade de Santa Cruz do Sul (UNISC); Professor Adjunto e Diretor de Assuntos Estratégicos, Relações Institucionais e Internacionais da Universidade Federal do Pampa (UNIPAMPA); Militante social de movimentos sociais de Direitos Humanos e Direito Humanitário em prol do desarmamento e controle de armas; Membro do International Steering Group da International Campaign to Abolish Nuclear Weapons (Prêmio Nobel da Paz 2017). E-mail: cristianwittmann@gmail.com
\end{abstract}

Recebido em: $17 / 11 / 2018$

Aprovado em: 28/04/2019

RESUMO: Este artigo trata da temática da autorregulação, global e policontextural que emerge na sociedade de risco contemporânea, em especial no que se refere às pesquisas com nanotecnologias. Utiliza-se da matriz teórica pragmático-sistêmica associada ao método dedutivo como caminho a responder à inquietação de pesquisa acerca dos limites e possibilidades da existência de meios de autorregulação frente à (in)existente regulação pelo Estado. Analisa-se a perda do monopólio do Estado, seja no seu ambiente interno nacional e no contexto global. Posteriormente a relação entre nanotecnologias e sociedade de risco para então vislumbrar um horizonte de instrumentos que já permite, embora enquanto resultado parcial, verificar que processos autorregulatórios já constituem uma realidade na sociedade e que esta ainda não conseguirá interagir se não superar a ingenuidade e acordar do sono profundo da exclusividade do Estado na regulação social.

Palavras-chave: Policontexturalidade regulatória; Nanotecnologias; Autorregulação.

\begin{abstract}
This article deals with the issue of autonomous, global and polycontextural selfregulation, emerging in contemporary risk society, particularly in relation to research on nanotechnology. Uses the pragmatic-systemic theoretical matrix associated with the deductive method as a way to respond to the following problem: the limits and possibilities of means of autonomous self-regulation in face of (in)existing state regulation. We analyze the loss of the monopoly of the state, either in their internal domestic and global context. Later the relationship between nanotechnology and society risk then envision a horizon instruments which already
\end{abstract}


allows, although as partial result, found that self-regulatory processes already a reality in society and that this interaction is still not able to overcome the ingenuity and not wake up from deep sleep of the exclusivity of the state in social regulation.

Keywords: Polycontextural regulation; Nanotechnologies; Self-Regulation.

SUMÁRIO: Introdução; 1 Estado e Regulação; 1.1 Alterações estruturais no monopólio do Estado; 1.2 A perda do monopólio para além dos muros da nação; 2 Riscos e Novas Tecnologias: a era das nanotecnologias; 2.1 Da incerteza ao risco; 3 Soberania Regulatória Versus Regulação Global acerca das Nanotecnologias.

\section{INTRODUÇÃO}

Este artigo apresenta resultados - não exaustivos - acerca da temática que envolve o marco regulatório das pesquisas envolvendo novas tecnologias, em especial as realizadas na escala nano, e consequentemente dos riscos dela provenientes, no contexto contemporâneo. As reflexões aqui presentes tendem a responder o questionamento acerca dos limites e possibilidades da existência de um modelo regulatório policontextural em decorrência dos contemporâneos contextos globais de regulação autônoma e dos contextos nacionais de regulação democrática.

A presente pesquisa apoia-se na matriz teórica pragmático-sistêmica ${ }^{1}$ e nas concepções sistêmico-complexas para a observação da sociedade oriundas da Teoria dos Sistemas Sociais como meio de superar o senso comum teórico dos juristas ${ }^{2}$. Enquanto método optou-se pelo dedutivo e bibliográfico, a partir dos preceitos de estudo de caso enquanto pesquisa aplicada visando a colaboração à reflexão de relevante controvérsia social.

Primeiramente buscar-se-á a reflexão sobre o estado da arte acerca dos novos desafios da regulação de temas de interesse coletivo e consequentemente no reconhecimento das insuficiências do Estado frente a emergência de uma nova ordem global. Posteriormente serão analisadas objetivamente as características das nanotecnologias e os riscos dela oriundos, restando por último a apresentação de um contexto de regulação plural e global já existente, gerando reflexões acerca dos limites e possibilidades da manutenção da ideia clássica de regulação tradicional.

\section{ESTADO E REGULAÇÃO}

Enquanto resultado de pesquisas no âmbito da regulação de situações de interesse da comunidade, o trabalho não pode deixar de tecer análise sobre o contexto no qual o Estado interage. Por tal motivo se mostra importante resgatar historicamente o papel e a formação da regulação pelo ente público ao mesmo tempo em que se estará denunciando as insuficiências do modelo de monopólio da função administrativa bem como demonstrando caminhos contemporâneos e, portanto, consensuais de regulação.

\footnotetext{
${ }^{1}$ ROCHA, Leonel Severo. Epistemologia Jurídica e Democracia. São Leopoldo: UNISINOS, 1998, p. 90.

${ }^{2}$ WARAT, Luis Alberto. Saber crítico e senso comum teórico dos juristas. Revista Sequência. Florianópolis, v. 03, n. 05, p. 48-57, 1982.
} 
Conforme a matriz epistemológica com a qual se trabalha pode-se inferir que também há uma mudança de percepção sobre a própria compreensão da função jurídica em meio a esta complexidade regulatória: "un sistema funcionalmente diferenciado de la sociedad moderna [...] cuya función es mantener estables las expectativas [...] aun en caso de que resulten vanas"3. Sendo que o que se observa depende do observador ${ }^{4}$, pode-se dizer que o sistema jurídico, enquanto autopoiético mantém-se auto-referencial ${ }^{5}$, em que seus elementos são produzidos e reproduzidos pelo próprio sistema, graças a uma sequência interna de interação circular e fechada ${ }^{6}$.

Nestas interações, como já é de se concluir, Luhmann identifica a comunicação como o elemento central das redes sociais, utilizado como modo particular de reprodução pelos sistemas sociais autopoiéticos. As comunicações são produzidas e reproduzidas, formando uma rede de comunicação que constituem os elementos do sistema e que não podem existir externamente. Essa rede de comunicação se auto-reproduz em uma produção de pensamentos e significados que se sucedem dando origem a outras comunicações, constituindo um contexto comum de significado, continuamente sustentado por novas comunicações. ${ }^{7}$

Mesmo sem a pretensão de exaustão, promover-se-á a apresentação de novas comunicações que tendem a permitir a observação de novos contornos e formas de regulação autônoma que estão emergindo, inclusive sobre nanotecnologias, e que não necessariamente levam em conta os critérios exclusivos do Estado, até mesmo porque monopólio da comunicação é algo incompatível com a própria matriz epistemológica aqui utilizada. Privilegia-se, a partir destes novos referenciais teóricos, os locais de observação a partir dos quais as comunicações se reproduzem.

\subsection{Alterações estruturais no monopólio do Estado}

Já não é de hoje que se denunciam as crises do Estado. Rotineiramente tem sido contundentemente apontadas crises no âmbito conceitual, estrutural - também envolvendo a crise fiscal, ideológica e filosófica, a crise institucional, funcional e política ${ }^{8}$. Todavia, paradoxalmente, o Estado segue funcionando e mantendo determinadas funções e monopólios. Parece que as reconhecidas crises que passa o Estado são crises de percepção do mesmo das atividades que historicamente desempenhava mas, que hoje adquirem uma roupagem diferenciada, global.

Tal forma de observação reflete, necessariamente, como o Estado sempre exerceu suas atividades quando da regulação dos interesses coletivos. Nesse contexto cabe lembrar dos conceitos clássicos que sempre envolveram a atuação do ente público, ressaltando a sua característica

\footnotetext{
${ }^{3}$ CORSI, Giancarlo; ESPOSITO, Elena; BARALDI, Claudio. Glosario sobre la teoría Social de Niklas Luhmann. Cidade do México: Universidad Iberoamericanaglossário, p. 52.

${ }^{4}$ Cf. MATURANA, Humberto; VARELA, Francisco. El arbol del conocimiento: Las bases biologicas del conocimiento humano. Madrid: Debate, 1996.

${ }^{5}$ TEUBNER, Gunther. O Direito como sistema autopoiético. Tradução de José Engracia Antunes. Lisboa: Fundação Calouste Gulbenkian, 1989, p. 32 e seguintes.

${ }^{6}$ Convém mencionar que ao falar em interação circular e fechada, está se falando no processo de clausura operacional, uma operação interna do sistema essencial para assegurar a identidade do sistema e logo, possibilitar sua abertura. Também ao se referir à interação circular estamos nos referendo não a um circulo vicioso, mas a um circulo virtuoso, onde ocorre sempre uma perspectivação em espiral. É o que se denomina hiperciclo. Ver: TEUBNER, Gunther. O Direito como sistema autopoiético. Tradução de José Engracia Antunes. Lisboa: Fundação Calouste Gulbenkian, 1989, pp. 95 - 126.

${ }^{7}$ CAPRA, Fritjof. As conexões ocultas: ciência para uma vida sustentável. Tradução de Marcelo Brandão Cipolla, São Paulo: Cultrix, 2002, p. 94-95.

${ }^{8}$ Cf. MORAIS, José Luis Bolzan de. As crises do estado e da constituição e a transformação espaço-temporal dos direitos humanos. 2. ed. Porto Alegre: Livraria do Advogado, 2011.
} 
principal, ou seja, o monopólio da função administrativa. Marçal Justem Filho aponta, ao comentar o ramo administrativista do Direito, que "usualmente, o direito administrativo é definido como o conjunto de normas que disciplina a função administrativa do Estado e a organização e o funcionamento dos sujeitos e órgãos encarregados de seu desempenho" 9 . A partir disso pode-se verificar as bases do exercício exclusivo por parte do Estado da regulação, dentre outras atividades do ente público e da administração pública. O próprio

[...] direito público e o direito administrativo em particular foi estruturado, durante largo tempo, como um instrumento de controle do poder e de exercício do poder. Limitava e legitimava a atuação do Poder Público, permanentemente em busca de uma equação de equilíbrio entre prerrogativas especiais de supremacia do Poder Público sobre a situação jurídica do particular e sujeições especiais que condicionavam de forma mais estrita a ação do Administrador. [...] Essa equação permanece relevante e útil para caracterizar o próprio direito administrativo. ${ }^{10}$

Esse paradigma, cunhado em divisões cartesianas históricas, não está inserido dentro da pactuação democrática, ou seja, de um Direito produzido democraticamente e não unilateralmente por parte da Administração Pública. Não se trata de discutir se o posicionamento do Estado Democrático de Direito deve como um todo pautar-se pela abstenção ou pela intervenção, e sim ao mesmo tempo tanto o lado da proteção quanto o da concretização de uma prerrogativa constitucional. Além da superação da dicotomia entre abstenção e intervenção, ainda deve-se levar em consideração que a organização administrativa aumentou em extensão, ocorreu a multiplicação das organizações públicas com status autônomo, empresas e instituições econômicas estatais em regime de autonomia de gestão, a ascensão da sociedade na direção do Estado e o próprio acesso aos centros de decisão por intermédio de grandes organizações ${ }^{11}$.

Não é exclusividade do Brasil a roupagem democrática que o Estado assumiu na contemporaneidade. Nesse contexto privilegiado tem-se de atentar para que a produção democrática, plural entre as mais diferentes organizações e sistemas sociais, não seja somente um simulacro - parâmetros novos que se mostram incompatíveis com o monopólio da realização do interesse público, do uso da força e da exclusividade da regulação por parte do ente público. Modesto $^{12}$ aborda uma nova organização administrativa, fundada em acordos, consensos e na conciliação de interesses e principalmente pela multiplicidade de entidades compostas por consenso de pluralidade de administrações e por órgãos ou entidades mistas o que afeta, necessariamente, a própria identificação dos limites do Direito produzido pelo Estado brasileiro. Nesse contexto pode-se afirmar que "a Constituição implica, então, uma circulação estrutural básica entre administração (no sentido amplo dos procedimentos dos órgãos competentes para a tomada de decisão política e sua execução, política (no sentido estrito, como os processos de

\footnotetext{
${ }^{9}$ JUSTEN FILHO, Marçal. Curso de Direito Administrativo. 8. ed. Belo Horizonte: Fórum, 2012, p. 67.

${ }^{10}$ MODESTO, Paulo. O direito administrativo do terceiro setor: a aplicação do direito público às entidades privadas sem fins lucrativos. Revista de Direito da Procuradoria Geral: Rio de Janeiro. Rio de Janeiro, edição especial, p. 237259, 2012, p. 240, grifos no original.

${ }^{11}$ GARCÍA-PELAYO, Manuel. As transformações do Estado Contemporâneo. Rio de Janeiro: Forense, 2009, p. 9397

${ }^{12}$ MODESTO, Paulo. O direito administrativo do terceiro setor: a aplicação do direito público às entidades privadas sem fins lucrativos. Revista de Direito da Procuradoria Geral: Rio de Janeiro. Rio de Janeiro, edição especial, p. 237259, 2012, pp. 242-243.
} 
formação de programas partidários e escolha entre pessoas e programas), público como receptor das decisões e povo como o público enquanto reage ativamente às decisões da administração" ${ }^{13}$.

Aproxima-se dessa forma dos preceitos de co-evolução propostos por Teubner. Esse grau de interações surge com os estímulos procedentes de vários subsistemas - bem como de instituições. Com tais interações passa-se ao aprendizado recíproco entre os contextos - neste caso o Estado e as instituições civis que posteriormente trazem a exigência de compatibilidade entre as estruturas de expectativas neste grande contexto de interações. Defende o autor que essa convergência de expectativas pode ser estimulada com a "introdução voluntária de mecanismos de regulação" que permitem adentrar "no domínio de uma regulação da co-evolução, onde sistemas de negociação intersistémicos são desenhados com o objectivo precípuo de compatibilizar mundividências e expectativas convergentes"14. A mesma compreensão proposta pelo autor também se aplica no cenário global que, por fins didáticos, se apresenta separado.

\title{
1.2 A perda do monopólio para além dos muros da nação
}

Historicamente tem-se denominado a região, esfera, parcela de decisão externa aos limites territoriais do Estado como internacional. A própria referência na etimologia da palavra nos proporciona a compreensão prévia de que se trata de uma região dominada pelas mais diversas nações, um espaço entre nações e dessa maneira internacional. A proposta metodológica aqui nos indica que a melhor denominação para a nova ordem que emerge dos mais plurais contextos a margem do Estado como uma ordem global, o que Gunther Teubner denomina como direito global, ou seja, não 'inter-nacional':

\begin{abstract}
o direito global (não: 'inter-nacional'!), nesse sentido, é um ordenamento jurídico sui generis que não pode ser avaliado segundo os critérios de auferição de sistemas jurídicos nacionais. [...] esse ordenamento jurídico, já amplamente configurado nos dias atuais, distingue-se do direito tradicional dos Estados-nações por determinadas características, que podem ser explicadas por processos de diferenciação no bojo da própria sociedade mundial. Porque, por um lado, se o direito global possui pouco respaldo político e institucional no plano mundial, por outro lado, ele está estreitamente acoplado a processos sociais e econômicos dos quais recebe os seus impulsos mais essenciais. ${ }^{15}$
\end{abstract}

O próprio autor aborda algumas situações, como prerrogativas de um cidadão global de Direitos Humanos que afastam os Estados, a proteção ambiental em tendência de uma globalização do Direito e até mesmo a polêmica lex sportiva internationalis. O fato de que o acoplamento estrutural entre a Política e o Direito não possuir uma clara correspondência no plano da sociedade global $^{16}$ corrobora a situação de que o jurídico/político centralmente produzido pelo Estado ou entre nações (internacional) passa a ser cada dia mais marginal frente às comunicações jurídicas dos juristas, das decisões pragmáticas dos conflitos jurídicos e dessa maneira do direito vivo global.

Não se busca aqui confrontar e advogar por uma inexistência de um regime internacional de normas jurídicas que condicionam a política e muito menos a inexistência da politização do jurídico nesta esfera supranacional. O objetivo é ultrapassar a ingenuidade que ainda paira sobre

\footnotetext{
${ }^{13}$ NEVES, Marcelo. Transconstitucionalismo. São Paulo: Martins Fontes, 2009, pp. 58-59.

${ }^{14}$ TEUBNER, Gunther. O Direito como sistema autopoiético. Tradução de José Engracia Antunes. Lisboa: Fundação Calouste Gulbenkian, 1989, p. 125.

15 TEUBNER, Gunther. A Bukowina Global sobre a Emergência de um Pluralismo Jurídico Transnacional. Revista Impulso. Piracicaba, 14(33): 9-31, 2003, p. 11.

${ }^{16}$ LUHMANN, Niklas. El Derecho de la Sociedad. 2. ed. Cidade do México: Herder, 2005.
} 
as instituições jurídicas e seus aplicadores de que o Estado é a única instituição capaz de criar normas que permitem a generalização e a organização das expectativas por parte de diferentes atores sob o ponto de vista pragmático. Um grande exemplo é o que hoje se conceitua enquanto constituições civis transnacionais de maneira a relacionar diferentes instituições intersistêmicas por meio do acoplamento de normas jurídicas secundárias que orientam, fundamentadas em princípios

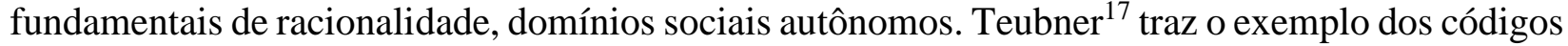
corporativos, os quais emergem de um fenômeno jurídico da constitucionalização dos regimes de governança privados. São, na realidade, exemplos de um Direito Reflexivo, ou seja, quando o "sistema jurídico se identifica a si mesmo como um sistema autopoiético num mundo de sistemas autopoiéticos, e extrai dessa auto-identificação consequências operacionais" ${ }^{18}$.

Embora os Estados nacionais e a sua ordem internacional propiciem induções de expectativas e comportamentos não é mais possível fechar os olhos para a nova ordem. Exemplos da ordem internacional instituída e a condução de expectativas são várias que exemplificativamente toma-se o desarme internacional, onde mesmo não estando obrigados por instrumentos o estigma moral criado pela conduta de vários Estados impõem a conduta àquele que ainda não aderiu ao instrumento proibitivo - como é o caso do Tratado de Banimento das Minas Terrestres e os Estados Unidos da América que, mesmo não aderindo ao tratado, não produz minas terrestres antipessoal desde o início da década de $1990^{19}$. De outro lado também podem-se encontrar exemplos oriundos da generalização de expectativas e consequentemente comportamentos a partir de instrumentos jurídicos que os Estados não colaboraram como as constituições civis, os códigos de conduta das empresas transnacionais, os compliance programs e até mesmo as normas oriundas da International Organization for Standardization, comumente conhecidas por normas de padronização ISO, também possuem características de autonomia frente à produção normativa Estatal $^{20}$. Determinado grau de ingenuidade reflete-se em não reconhecer que os ambientes autônomos de regulação procedem com determinada indiferença quanto a sua adequação (quiçá compatibilidade/convergência de suas expectativas) ao meio regulatório que os envolve, bem como possuem, pela natureza transnacional (global) da sua aplicação uma imunidade frente as medidas político-regulatórias produzidas nos contextos externos às suas organizações ${ }^{21}$.

Para além da dicotomia entre o nacional do global, há de se compreender que na realidade tem-se uma sociedade que se diferencia entre sistemas sociais autopoiéticos - a base para a compreensão reflexiva do Direito como abordado. Dito isso pode-se inferir que "a concepção aqui escolhida nega categoricamente ao direito oficial estatal qualquer posição hierárquica superior, orientando-se, antes, pela imagem de diversos discursos jurídicos encontrados em níveis iguais" 22 ,

\footnotetext{
${ }^{17}$ TEUBNER, Gunther. The Corporate Codes of Multinationals: Company constitutions beyond corporate governance and co-determination. IN. NICKEL, Rainer (Ed.). Conflict of Laws and Laws of Conflict in Europe and beyond: patterns of supranational and transnational juridifaction. Hart: Oxford, 2009, pp. 261-275, p. 263.

18 TEUBNER, Gunther. O Direito como sistema autopoiético. Tradução de José Engracia Antunes. Lisboa: Fundação Calouste Gulbenkian, 1989, p. 138.

${ }^{19}$ Cf. VIEIRA, Gustavo Oliveira. Inovações em Direito Internacional: um estudo de caso a partir do Tratado de Ottawa. Santa Cruz do Sul: EDUNISC, 2006.

${ }^{20}$ Cf. ENGELMANN, Wilson. O diálogo entre as fontes do Direito e a gestão do risco empresarial gerado pelas nanotecnologias: construindo as bases à juridicização do risco. IN: STRECK, Lenio L.; ROCHA, Leonel S.; ENGELMANN, Wilson (Orgs). Constituição, Sistemas Sociais e Hermenêutica: anuário do Programa de PósGraduação em Direito da UNISINOS: Mestrado e Doutorado. Porto Alegre: Livraria do Advogado, 2012, n. 9, p. 319344.

${ }^{21}$ TEUBNER, Gunther. O Direito como sistema autopoiético. Tradução de José Engracia Antunes. Lisboa: Fundação Calouste Gulbenkian, 1989, p. 154.

22 TEUBNER, Gunther. Direito, sistema e policontexturalidade. São Paulo: UNIMEP: 2005, p. 89.
} 
mas salienta-se que em posições diferentes de observação, corroborando com a idéia de centro e periferia do sistema. A diferença entre centro e periferia de um sistema social - o Direito por exemplo - depende do local de observação, ponto de referência.

Conforme abordado, não se trata de analisar exaustivamente o tema. Alerta-se aqui, da mesma forma que existe uma insuficiência e a emergência de um novo modelo nacional de regulação e administração do bem comum, surge na esfera global uma nova ordem de normas e expectativas autônomas frente ao Estado. Não necessariamente há uma sobreposição de tais normas, mas sim uma tendência de convívio entre os diferentes sistemas, pois esta é uma importante condição para o sucesso dessa nova ordem ${ }^{23}$.

\section{RISCOS E NOVAS TECNOLOGIAS: a era das nanotecnologias}

Em que pese as nanotecnologias ainda serem uma novidade na sociedade e a mesma ainda não lograr formas de compreensão harmoniosas sobre o tema, a referida tecnologia remete à década de 1950. Richar Phillips Feynman, Prêmio Nobel de Física de 1950, anuncia em uma conferência sob o título "There's Plenty of Room at the Bottom" que na análise molecular até então realizada não conseguia visualizar que havia muito espaço lá embaixo ${ }^{24}$. Todavia foi Eric Drexler, do Instituto Foresight, que “[...] acuñó los términos de 'nanociencia' y 'nanotécnica' que implican el manejo y disposición de átomos y moléculas que darán origen a productos más livianos, de una mayor resistencia, más ecológicos y económicos que los actuales"25 (CASTAGNINO, 2007, p. 1).

A nanociência trabalha com tecnologias em que seus produtos se apresentam em uma dimensão nunca antes pensada, ou seja, um bilionésimo de metro. Neste aspecto tais tecnologias “[...] prospectam a produção de objetos, equipamentos e produtos que estão aproximadamente em torno da escala de 1 a 100 nanômetros (nm), ou seja, 10-9 de ordem de grandeza" 26 . É importante frisar que "las diferencias entre microtécnica y nanotécnica no residen en el tamaño sino en las propiedades físicas que cambian por la relación superficie-volumen del objeto" e é "en este cambio de propiedades es donde se definen las fronteras de la nanotecnología [...]”. Neste aspecto vale ressaltar a característica de que a manipulação das diferentes características de cada substância nesta escala traz como resultado diferentes resultados que antes não estavam presentes nos equivalentes convencionais. É importante trazer a cena uma das principais advertências do seu descobridor, ou seja, a de que não se deverão combinar átomos e moléculas de tal forma que o resultado de tal combinação fique quimicamente instável ${ }^{27}$. Dito isso, ressalta-se que "[...] não se

\footnotetext{
${ }^{23}$ TEUBNER, Gunther. The Corporate Codes of Multinationals: Company constitutions beyond corporate governance and co-determination. IN. NICKEL, Rainer (Ed.). Conflict of Laws and Laws of Conflict in Europe and beyond: patterns of supranational and transnational juridifaction. Hart: Oxford, 2009, pp. 261-275, p. 271.

${ }^{24}$ FEYNMAN, Richard P. There's Plenty of Room at the Bottom: an invitation to Enter a New Field of Physics. Palestra proferida em 29 de dezembro de 1959, por ocasião da Reunião Anual da Sociedade Americana de Física, no California Institute of Technology (CALTECH). Disponível em <http://www.zyvex.com/nanotech/feynman.html> acesso em 10 de novembro de 2014.

25 CASTAGNiNO, Juan M.. Técnicas, materiales y aplicaciones en nanotecnología. Acta bioquím. clín. latinoam. [online]. 2007, vol.41, n.2, pp. 189-191.

${ }^{26}$ ENGELMANN, Wilson. A (re)leitura da teoria do fato jurídico à luz do 'diálogo entre as fontes do direito': abrindo espaços no direito privado constitucionalizado para o ingresso de novos direitos provenientes das nanotecnologias. In: CALLEGARI, A. L; STRECK, L. L; ROCHA, L. S (Org). Constituição, Sistemas Sociais e Hermenêutica. Porto Alegre: Livraria do Advogado, 2010, pp 289-308, p. 299.

${ }^{27}$ FEYNMAN, Richard P. There's Plenty of Room at the Bottom: an invitation to Enter a New Field of Physics. Palestra proferida em 29 de dezembro de 1959, por ocasião da Reunião Anual da Sociedade Americana de Física, no
} 
tem ainda uma certeza científica quanto aos potenciais toxicológicos que as atividades, sejam de pesquisa e de produção ou de consumo, em nano escala, poderão provocar em relação às pessoas e ao meio ambiente" 28 .

O status demonstrado mostra que as nanotecnologias são, ademais a tudo, uma forma de intervenção humana no sistema natural que, se sabe, possui uma dinâmica natural a partir dos preceitos biológicos da autopoiese bem demonstrada pelos biólogos chilenos Humberto Maturana e Francisco Varela ${ }^{29}$. Nesse contexto a manipulação de átomos e moléculas proporciona novos desafios aos humanos, e dentre eles a possibilidade de criação de direitos e obrigações inéditos. Esse é o debate acerca dos reflexos das "potenciais desconhecidas consequências" das nanotecnologias.

\subsection{Da incerteza ao risco}

Há grande incerteza científica sobre as consequências futuras dos atos presentes. Compreender a imersão em uma sociedade de risco, coloca a incerteza como um dos temas principais das comunicações. Busca-se uma compreensão da noção de risco desde um âmbito de ação singular a um âmbito coletivo. Para tanto torna-se necessário que a ciência jurídica abra mão de seu unilateralismo e deixe sua cegueira unidimensional ${ }^{30}$ de lado buscando aportes em outras ciências, tal como se busca na sociologia uma abordagem mais profunda sobre risco.

No que tange às consequências das nanotecnologias há de se considerar que os riscos são diversos, seja pelo impacto negativo ou sobre os logros positivos para a natureza e sociedade e nesse contexto "na sociedade complexa o risco torna-se um elemento decisivo"31. Há neste debate entre nanotecnologias, inovação tecnológica, sociedade de risco, equidade intergeracional e a sociedade uma complexidade sistêmica inédita que, todavia, ingressa no ambiente jurídico por meio da compreensão dos riscos que envolvem e ameaçam o direito à sustentabilidade. Para Leonel Severo Rocha o risco está associado às possibilidades de decidir, fazendo então a diferenciação entre risco e perigo quando de decisões contingentes:

\footnotetext{
na sociedade complexa o risco torna-se um elemento decisivo. O risco é um evento generalizado da comunicação, sendo uma reflexão sobre as possibilidades de decisão. Na literatura tradicional, o risco vem acompanhado da reflexão sobre segurança. Nesta ótica, Luhmann prefere colocar o risco em oposição com o perigo, por entender que os acontecimentos sociais são provocados por decisões contingentes (poderiam ser de outra forma), que não permitem mais se falar de decisão segura. ${ }^{32}$
}

\footnotetext{
California Institute of Technology (CALTECH). Disponível em <http://www.zyvex.com/nanotech/feynman.html> acesso em 10 de novembro de 2012.

${ }^{28}$ Cf. ENGELMANN, Wilson. As Nanotecnologias e a Gestão Transdisciplinar da Inovação. In: , Wilson (Org.) As novas tecnologias e os Direitos Humanos: os desafios e as possibilidades para construir uma perspectiva transdisciplinar. Curitiba: Editora Honoris Causa, 2011, pp. 297-336.

${ }^{29}$ Ver MATURANA, Humberto R.; VARELA, Francisco J. De máquinas e seres vivos: autopoiese - a organização do vivo. Porto Alegre: Artes Médicas, 1997.

${ }^{30}$ MORIN, Edgar. Ciência com consciência. Rio de Janeiro: Bertrand Brasil, 2002.

${ }^{31}$ ROCHA, Leonel Severo; SCHWARTZ, Germano; CLAM, Jean. Introdução à Teoria do Sistema Autopoiético do Direito. Porto Alegre: Livraria do Advogado, 2005, p. 36.

32 ROCHA, Leonel Severo. Epistemologia jurídica e democracia. São Leopoldo: UNISINOS, 1998, p. 99. ver também ROCHA, Leonel Severo; SCHWARTZ, Germano; CLAM, Jean. Introdução à Teoria do Sistema Autopoiético do Direito. Porto Alegre: Livraria do Advogado, 2005, p. 36.
} 
Tendo como referência essas categorias de risco e perigo percebe-se que essa diferenciação se dá pelo ponto de observação, ou seja, aquele que decide e aqueles que se encontram à deriva sofrendo frente às decisões/riscos tomadas por outros. Dessa forma,

os riscos diferem [...] dos perigos, porque identificam uma fase do desenvolvimento da modernidade em que interpretação das diversas ameaças a que a sociedade sempre está exposta ao longo da história passa a ser realizada, compreendendo-as como condicionadas diretamente à atividade humana, abandonando a leitura que as associava aos destinos coletivos. Convive-se agora com um perfil dos riscos específico das novas sociedades, que não se identifica a contextos espaciais ou temporais particulares, e não mais expressa o resultado exclusivo de eventos involuntários e naturais. ${ }^{33}$

Risco está associado à perda potencial como consequência de uma decisão, ao ponto que perigo se atrela às perdas potenciais causadas externamente. Tendo em vista os conceitos de racionalidade na identificação dos riscos, sugere-se logicamente que a sociedade moderna pode ser considerada uma sociedade de risco, ao ponto em que as sociedades antigas são abordadas como sociedades de perigo, tendo em vista a não existência de percepção na identificação das possibilidades de perda frente às decisões tomadas.

Para Niklas Luhmann, risco é "una forma para realizar descripciones presentes del futuro desde el punto de vista de que uno puede decidirse, en atención a los riesgos, por una alternativa o otra" 34 , ou seja, decisões particulares no presente trazem as possibilidades de danos futuros e condicionam o que acontecerá no futuro. Dessa forma, o risco está ligado intimamente com a tomada de decisão (decidir de uma maneira ou de outra) frente à(s) possibilidade(s) de conseqüência(s) negativa(s) em um futuro condicionado pelas decisões do presente. Já no ponto de vista de Raffaelle De Giorgi, através do ponto de vista sistêmico luhmanniano, afirma que:

a sociedade, em outras palavras, usa um "medium", ou seja, uma forma da constituição de formas para a representação do futuro e para produzir vínculos com o futuro. A forma dessa representação e a modalidade da produção destes vínculos com o futuro chama-se risco. $\mathrm{O}$ "medium" no qual o risco possibilita a construção de outras formas é o "medium" probabilidade/improbabilidade. ${ }^{35}$

Percebe-se que a construção do futuro pela decisão presente está associada ao binômio, ou medium, da probabilidade ou improbabilidade de tais consequências se tornarem realidade. Da mesma forma que uma decisão jurídica associa-se modernamente ao binômio legal ou ilegal, a decisão contemporânea incorpora aspectos jurídicos, políticos e econômicos, também passam a refletir sobre a probabilidade de tais consequências acontecerem.

Esses conceitos se tornam pertinentes no momento em que se encontra uma sociedade de risco em contrapartida do fato da sociedade industrial ter se tornado obsoleta, ou seja, vive-se

\footnotetext{
${ }^{33}$ LEITE, José Rubens Morato; AYALA, Patryck de Araújo. Direito ambiental na sociedade de risco. Rio de Janeiro: Forense Universitária, 2004, p. 13.

${ }^{34}$ Luhmann, Niklas. Complejidad y modernidad: De la unidad a la diferencia. Madrid: Editorial Trotta, p. 163.

${ }^{35}$ DE GIORGI, Raffaele. O risco na sociedade contemporânea. In Revista Seqüência - Revista do Curso de PósGraduação em Direito da Universidade Federal de Santa Catarina, ano 15, n. 28, junho de 1994, p. 5. Disponível em http://www.buscalegis.ufsc.br/, acessado em 28 de março de 2013.
} 
[...] uma fase no desenvolvimento da sociedade moderna, em que os riscos sociais, políticos, econômicos e individuais tendem cada vez mais a escapar das instituições para o controle e a proteção da sociedade industrial. ${ }^{36}$

A reflexão anterior demonstra o estágio complexo da sociedade na qual a possibilidade de decidir e logicamente causar impactos significativos ao coletivo está disseminada. Os exemplos são os mais diversos, considerando inclusive as nanotecnologias. Seja a existência quanto a inexistência de marco regulatório não impedem determinadas decisões acerca de tais manipulações. A grande diferença é que a regulação por parte do Estado, ou seja, com relação procedimento autoregulatório autônomo global - alheio ao ente público, sobre determinado aspecto das nanotecnologias interfere que os riscos passem a estarem institucionalizados nos diferentes sistemas sociais e instituições, seja pela centralidade ou na periferia dessas comunicações. $\mathrm{O}$ Estado, quando regula, permite assim outros graus de institucionalização na sociedade - inclusive dos seus riscos.

A diferença de uma sociedade moderna, diferenciada em classes, da sociedade de risco é que ao contrário da riqueza a racionalidade passa a estar associada à exposição ao risco.

[...] o risco é um conceito que tem sua origem na modernidade, dissociando-se de uma dimensão de justificação mítica e tradicional da realidade, relacionada com a verificação de contingências, eventos naturais e catástrofes, atribuídos a causas naturais e à intervenção divina, para se aproximar de uma dimensão que seleciona como objetos as consequências e os resultados de decisões humanas [...] e que se encontram associadas ao processo civilizacional, à inovação tecnológica e ao desenvolvimento econômico gerados pela industrialização. ${ }^{37}$

Esse é o debate acerca dos reflexos das "potenciais desconhecidas consequências" das nanotecnologias. Não se pode analisar de forma ingênua a questão e adotar qualquer alteração no ecossistema como dano ambiental, eis que o viver humano pode ser então analisado enquanto morte no nascimento $^{38}$ tendo em vista o grande impacto que produz:

seria excessivo dizer que todas as alterações no meio ambiente vão ocasionar um prejuízo, pois desta forma estaríamos negando a possibilidade de mudança e de inovação, isto é, estaríamos entendendo que o estado adequado do meio ambiente é o imobilismo, o que é irreal. Contudo, o admitirmos mudanças espontâneas ou até provocadas pela natureza não nos conduz a afirmar que todas essas mudanças são benéficas. ${ }^{39}$

Há grande incerteza científica sobre as consequências futuras dos atos presentes. Compreender a imersão em uma sociedade de risco, coloca a incerteza como um dos temas principais das comunicações. Busca-se uma compreensão da noção de risco desde um âmbito de ação singular a um âmbito coletivo. Vincula-se, como nunca antes, a prática presente com as consequências futuras. Trata-se da igualdade entre gerações, estabelecendo que cada geração passe um legado ambiental que permita o próprio desenvolvimento - sem esquecer sua vinculação

\footnotetext{
${ }^{36}$ BECK, Ulrich. A reinvenção da política: rumo a uma teoria da modernização reflexiva. In: Ulrich; GIDDENS, Anthony; LASH, Scott. Modernização reflexiva: política, tradição e estética na ordem social moderna. São Paulo: Editora da Universidade Estadual Paulista, 1997, p. 15.

${ }^{37}$ LEITE, José Rubens Morato; AYALA, Patryck de Araújo. Direito ambiental na sociedade de risco. Rio de Janeiro: Forense Universitária, 2004, p. 12-13.

${ }^{38}$ HAWKEN, Paul. The Ecology of Commerce: a declaration of sustainability. New York: HarperCollins Publishers, 1993, p. 19-36.

${ }^{39}$ MACHADO, Paulo Affonso Leme. Direito Ambiental Brasileiro. São Paulo: Malheiros, 2000, p. 323.
} 
sustentável - das futuras gerações. Não há dúvida, neste ponto, que o perigo das nanotecnologias se traduz também em uma ameaça potencial para as futuras gerações, estando em jogo a proteção jurídica já existente baseada na equidade intergeracional:

a noção de equidade intergeracional consiste em um desdobramento do próprio princípio do desenvolvimento sustentável, detendo o significado de que as presentes gerações têm o dever intergeracional de deixar às futuras gerações um 'patrimônio ambiental' compatível com suas necessidades ${ }^{40}$

Embora já existam parâmetros de regulamentação oriundos do Estado, e além dele, em torno da eliminação dos riscos ambientais - precaução - ou do controle deles - prevenção, ainda padece de uma relevante análise específica para as nanotecnologias. Conforme se observa a inexistência de norma jurídica oriunda dos limites do Estado não impede o surgimento espontâneo e autônomo de regulamentações esparsas.

Neste ponto é que se busca chamar a atenção para a situação da regulação autônoma, muitas vezes global, que diferentes instituições estão criando e dessa maneira limitando os avanços das pesquisas com nanotecnologia por diferentes critérios, que dentre eles inclui o risco futuro. A institucionalização dos riscos, característica marcante do novo perfil de sociedade global não mais estatizada em classes, ocorre nos mais diferentes contextos organizacionais e tendem a uma convergência para uma maior efetividade e consequente eficácia embora, em decorrência da clausura operativa de cada instituição e subsistema, seja percebido determinado grau de imunidade e indiferença com a regulação praticada em outros contextos ${ }^{41}$. Com o exposto pode-se avançar para a problematização da ideia da consequente fragilização da soberania em torno da regulação global em torno dos limites aos avanços tecnológicos oriundos das nanotecnologias e seus riscos.

\section{SOBERANIA REgUlatória VERSUS REgulaÇÃo GLOBAL ACERCA DAS NANOTECNOLOGIAS}

Anteriormente foram expostas as perdas do monopólio do Estado seja na esfera nacional quanto na esfera internacional. No contexto nacional o monopólio da função administrativa, e consequentemente de regulação, já não mais é exercida unicamente pelo ente público a partir da diferente gama de atores, em expansão, que atuam em colaboração ou até mesmo com determinado grau de autonomia. Ainda no ambiente interno é possível verificar que, com a inauguração da obrigação democrática no contexto estatal, abre-se um caminho em prol do diálogo no exercício da função administrativa e consequentemente na regulação. No global ocorre a tendência de que, mesmo não anulando as forças e a legitimidade que o Estado possui emerjam novos meios e métodos de regulação autônoma alheios à centralidade do ente público e dos ambientes formados pelas nações. Essa análise não pode ser estanque e observada somente a partir do desenvolvimento da estrutura social pós-industrial, ou seja, de risco ${ }^{42}$.

Seja na seara interna ou externa aos limites físicos do Estado, percebe-se que o mesmo

\footnotetext{
${ }^{40}$ CARVALHO, Delton Winter de. Dano ambiental futuro: a responsabilização civil pelo risco ambiental. Rio de Janeiro: Forense universitária, 2008, p. 47.

${ }^{41}$ TEUBNER, Gunther. O Direito como sistema autopoiético. Tradução de José Engracia Antunes. Lisboa: Fundação Calouste Gulbenkian, 1989, p. 154.

${ }^{42}$ Cf. BECK, Ulrich. A reinvenção da política: rumo a uma teoria da modernização reflexiva. In: Ulrich; GIDDENS, Anthony; LASH, Scott. Modernização reflexiva: política, tradição e estética na ordem social moderna. São Paulo: Editora da Universidade Estadual Paulista, 1997.
} 
passa a figurar em determinados momentos em situação periférica à regulação autônoma. Se o "risco consiste num processo de racionalização das incertezas inerentes a qualquer reflexão acerca do futuro, isto é, em processos de tomada de decisão imersos em contextos de racionalidade limitada"43, percebe-se que que tal racionalização das incertezas tende a estar disseminado a partir das diferentes comunicações geradas neste ambiente policontextural.

Eis que surge o dilema que envolve a soberania. Ressalta-se que a Constituição Federal em seus artigos iniciais torna claro expondo como um de seus fundamentos a soberania, sendo também respeitada os espaços externos a ele. Todavia o conceito de soberania não pode ser tido como estanque, imutável e carente de uma significação ao caso concreto e atual não mais compatível com as características historicamente fundadas no conceito de Rousseau em torno de um poder uno, inalienável e indivisível.

Em essa época de mudança existem ainda reflexões acerca das seguintes categorias de soberania: a afirmativa e a compartilhada. A primeira é uma maneira de flexibilizar as características históricas da soberania a partir de acordos internacionais a partir do conceito de direitos de soberania vinculados ao controle do Estado sobre seu território. Já a segunda, que pode ser confundida com ingerência externa impositiva, surge quando determinado Estado abre mão do monopólio de sua soberania para a emergência de uma simbiose entre duas nações ${ }^{44}$. Analisando ambos conceitos pode-se verificar que o dilema em questão ainda corre paralelamente de forma autônoma, já que a situação da regulação global (e não internacional) independe do Estado e consequentemente do seu monopólio.

Especificamente quanto às nanotecnologias o ambiente regulatório está muito incipiente em ambos contextos - oriundo também do momento inicial e multiplicador dos conhecimentos que envolvem as nano partículas. De outro lado as pesquisas envolvendo as nano materiais não param e o próprio termo nano tem sido utilizado amplamente para denominar produtos no seu formato reduzido - tais como "iPod nano", o chip de celular "nano simcard" e até mesmo agulhas. Mesmo que aparentemente estar ocorrendo o uso indevido do conceito "nano" induzindo o consumidor ao equívoco, este parece não ser o principal dos problemas. O que aqui se defende enquanto relevante - sem excluir as demais searas - é a regulação das pesquisas que sim envolvem substâncias na escala de uma bilionésima parte de um metro, ou seja, $10^{-9}$.

Frente a todas as dificuldades da regulação e eventualmente competição entre regulações há a necessidade de mudança de concepção. Corroborando com o dito anteriormente, "a concepção aqui escolhida nega categoricamente ao direito oficial estatal qualquer posição hierárquica superior, orientando-se, antes, pela imagem de diversos discursos jurídicos encontrados em níveis iguais" 45 . Neste contexto é que as normas, sejam as oriundas do Estado ou não, convivem em uma globalização policêntrica. Para que a regulação tenda a ser bem-sucedida torna-se necessário que os programas auto-regulativos concretos do direito 'coincidentemente' co-evoluam com os programas de regulação autônoma concretos oriundos dos demais sistemas sociais. Lembra-se que as intervenções entre dois sistemas devem ser compreendidos enquanto observações recíprocas onde ambos os sistemas atuam a partir de uma comunicação hermeticamente fechada e autônoma,

\footnotetext{
${ }^{43}$ CARVALHO, Delton. O Direito dos desastres ambientais e o gerenciamento circular do risco. In: BARRETO, Vicente P.; DUARTE, Francisco C.; SCHWARTZ, Germano. (Orgs). Direito da Sociedade Policontextural. Curitiba: Appris, 2013, pp 349-376, p. 368.

${ }^{44}$ LOPES, Marcel A; GALVÃO, Silvano M.; COSTA E SILVA, Tatiana M. Soberania Ambiental. In: XV Congresso Nacional do CONPEDI/UEA - Manaus, 2006, Manaus. Anais eletronicos do XV Congresso Nacional do CONPEDI/UEA - $\quad$ Manaus. Manaus: CONPEDI, $2006 . \quad$ Disponível em: <http://www.conpedi.org.br/anais_manaus.html>. Acesso em: 14 set. 2013.

45 TEUBNER, Gunther. Direito, sistema e policontexturalidade. São Paulo: UNIMEP, 2005, p. 89.
} 
e "não existe ainda explicação teorética satisfatória acerca do modo como os sistemas autopoiéticos, essencialmente auto-regulatórios, podem regular outros sistemas" 46 .

$\mathrm{Na}$ conjuntura apresentada tem-se o aumento da relevância, especialmente quanto à regulação das nanotecnologias, dos programas de cumprimento e as próprias normas da International Organization for Standardization (ISO - na sigla em inglês).

Os programas empresariais de cumprimento voluntário, também conhecidos por compliance programs, são procedimentos sistematizados instituídos unilateralmente por alguma organização (privada ou pública) para assegurar que determinadas práticas impostas externa ou internamente sejam cumpridas. Dessa maneira tais programas assemelham-se às constituições civis denunciadas por Teubner quando da criação, autônoma, de normas jurídicas por organizações, sejam elas transnacionais ou não, que não necessariamente levam em conta os aspectos instituídos pelo Estado e, por consequência, colocam o ente público em uma posição de marginalidade em tais condutas.

Orientações como a criada pelo International Center for Technology Assessment indicam práticas para a supervisão de nanotecnologias e nanomateriais levam em consideração diferentes princípios e formas de orientação jurídica que atuam de forma de uma comunicação autônoma e em certa medida blindada à comunicação jurídica legitimada pelo Estado. Embora tratar-se de uma organização internacional a ISO trabalha autonomamente e tem editado diferentes documentos ${ }^{47}$ que permitem desde uma padronização das pesquisas ao mesmo tempo em que impõem limites e emitem orientações quanto ao gerenciamento dos riscos. Outra regulamentação existente é a série OECD sobre a segurança dos nanomateriais manufaturados produzido pela Organisation for Economic Co-operation and Development ${ }^{48}$.

Teubner vai desenvolver a compreensão de que a co-evolução entre os diferentes marcos autorregulatórios oriundos desse contexto policontextural parte não apenas de uma observação recíproca entre os sistemas e organizações. Tal contexto não identifica qualquer procedimento de interferência - até porque a irritação externa é sempre uma irritação interna do próprio sistema e nunca externa, mas sim de utilização de mecanismos de "leitura" do externo para a utilização pelo sistema com sua autorreferência.

Analisado isso é possível perceber uma mudança na concepção de monopólio interno e soberania externa do Estado. Ambas conceitos clássicos tendem a uma nova estrutura afim de manter-se neste contexto dinâmico de mudança onde não mais se permite a ingenuidade da exclusividade no exercício da função regulatória. $\mathrm{O}$ contexto policontextural de uma estrutura horizontal onde a diferença entre centro e periferia das comunicações somente permite uma compreensão a partir de cada local/sistema de observação. A expansão dos horizontes comunicacionais e a especialidade oportunizada pelas diferentes clausuras e códigos que tendem a serem produzidos no seio da sociedade somente ampliam as incertezas sobre qual o marco

\footnotetext{
${ }^{46}$ TEUBNER, Gunther. O Direito como sistema autopoiético. Tradução de José Engracia Antunes. Lisboa: Fundação Calouste Gulbenkian, 1989, p. 166.

${ }^{47}$ Tais como o IEC/TS 62622:2012, ISO/TR 12802:2010, ISO 10801:2010, ISO 10808:2010, ISO/TR 11360:2010, ISO/TS 12805:2011, ISO/TR 12885:2008, ISO/TS 12901-1:2012, ISO/DTS 12901-2, ISO/TR 13014:2012, ISO/TR 13121:2011, ISO/TS 27687:2008, ISO/TS 80004-1:2010, ISO/TS 80004-3:2010, ISO/TS 80004-4:2011, ISO/TS 80004-5:2011, ISO/DTS 80004-6 E ISO/TS 80004-7:2011. Todos disponíveis em: 〈http://www.iso.org>. Acesso em: 01 mar 2014[53.

${ }^{48}$ Cf. ENGELMANN, Wilson. O diálogo entre as fontes do Direito e a gestão do risco empresarial gerado pelas nanotecnologias: construindo as bases à juridicização do risco. IN: STRECK, Lenio L.; ROCHA, Leonel S.; ENGELMANN, Wilson (Orgs). Constituição, Sistemas Sociais e Hermenêutica: anuário do Programa de PósGraduação em Direito da UNISINOS: Mestrado e Doutorado. Porto Alegre: Livraria do Advogado, 2012, n. 9, p. 319344.
} 
regulatório que existirá, ou melhor, existirão.

Conforme se vislumbrou nas categorias que expõem as situações que flexibilizam a soberania, nenhuma delas parece estar associada ou ter determinada origem a partir da regulação autônoma realizada pelas diferentes instituições aqui apresentadas. Todavia, não há dúvida que a soberania estará submetida a uma nova percepção. Pela situação das nanotecnologias trazerem riscos não somente aos humanos, mas também ao seu ambiente é que resta o questionamento acerca da melhor qualificação acerca do debate de soberania ambiental, ou melhor, soberania da sustentabilidade, frente às consequências da autorregulação por parte de instituições alheias ao Estado. Resta assegurar que a indeterminação do Direito é uma característica inerente ao sistema, e dessa maneira nunca responderá com qualquer certeza frente aos riscos oriundos dessa sociedade que, pretensamente, tenta buscar garantias para a manutenção de suas expectativas neste código binário.

\section{CONCLUSÃO}

Primeiramente cabe reconhecer que a matriz epistemológica parece responder adequadamente às inquietações provocadas inicialmente, oportunizando categorias de observação diferenciadas. Enquanto resposta à problemática apresentada parece que não há dúvida acerca da existência de um marco regulatório policontextural, crescente no que tange às pesquisas com nanotecnologias.

Por sua vez, as preocupações demonstradas com o risco também aparecem como legítimas e disseminadas pela sociedade. Justamente ele passa a estar inerente a conceituação que essa sociedade recebe, ou seja, de risco e não mais diferenciada a partir de classes sociais. Ela já superou a fase industrial e sua compreensão sobre perigo com a crescente institucionalização dos riscos, seja quando da regulação por parte do Estado ou a autônoma global, a partir da racionalidade moderna.

A regulação, a partir das análises feitas, continua a existir e mantêm-se relevante para a manutenção das expectativas dos diferentes sistemas sociais e organizações que comunicam tais preocupações com o objeto da normatização. Todavia também há de se dizer que a regulação em nada diminui a incerteza dos riscos, positivos e negativos, aos quais se está submetendo pela própria natureza do risco no que tange sua probabilidade/improbabilidade de acontecer.

Independentemente da natureza do Estado percebe-se ser própria da sociedade, ou seja, da comunicação a emergência de processos autônomos de regulação. Esses procedimentos também apresentam-se alheios a existência ou não de regulação por parte do Estado, claro que potencializados em ambientes comunicacionais com estruturas mais flexíveis que a do ente público. Seja a regulação interna, democrática, como a global autônoma um caminho sem retorno percebe-se que há uma significativa convergência em tais marcos regulatórios que, com seu reconhecimento recíproco, tendem a coevoluir sistemicamente embora cada sistema atue com certa alienação frente as demais comunicações/regulações.

Quanto à soberania e o monopólio do Estado atenta-se para a necessária superação da cegueira unidimensional das suas exclusividades. Independentemente de sua vontade os processos regulatórios serão cada vez mais plurais e policontexturais, restando assim uma melhor compreensão da indeterminação do Direito e da sociedade para qualitativamente atuar nessa dinamicidade. Embora este trabalho proporcione mais dúvidas que propriamente resultados concretos, entende-se aqui enquanto resultado parcial de uma longa pesquisa de doutoramento. 


\section{REFERÊNCIAS}

BECK, Ulrich. A reinvenção da política: rumo a uma teoria da modernização reflexiva. In: Ulrich; GIDDENS, Anthony; LASH, Scott. Modernização reflexiva: política, tradição e estética na ordem social moderna. São Paulo: Editora da Universidade Estadual Paulista, 1997.

CAPRA, Fritjof. As conexões ocultas: ciência para uma vida sustentável. Tradução de Marcelo Brandão Cipolla, São Paulo: Cultrix, 2002.

CARVALHO, Delton Winter de. Dano ambiental futuro: a responsabilização civil pelo risco ambiental. Rio de Janeiro: Forense universitária, 2008.

CARVALHO, Delton. O Direito dos desastres ambientais e o gerenciamento circular do risco. In: BARRETO, Vicente P.; DUARTE, Francisco C.; SCHWARTZ, Germano. (Orgs). Direito da Sociedade Policontextural. Curitiba: Appris, 2013, pp 349-376.

CASTAGNINO, Juan M.. Técnicas, materiales y aplicaciones en nanotecnología. Acta bioquím. clín. latinoam. [online]. 2007, vol.41, n.2, pp. 189-191.

CORSI, Giancarlo; ESPOSITO, Elena; BARALDI, Claudio. Glosario sobre la teoría Social de Niklas Luhmann. Cidade do México: Universidad Iberoamericanaglossário.

DE GIORGI, Raffaele. O risco na sociedade contemporânea. In Revista Sequiência - Revista do Curso de Pós-Graduação em Direito da Universidade Federal de Santa Catarina, ano 15, n. 28, junho de 1994, p. 5. Disponível em http://www.buscalegis.ufsc.br/, Acesso em 28 de março de 2018.

ENGELMANN, Wilson. A (re)leitura da teoria do fato jurídico à luz do 'diálogo entre as fontes do direito': abrindo espaços no direito privado constitucionalizado para o ingresso de novos direitos provenientes das nanotecnologias. In: CALLEGARI, A. L; STRECK, L. L; ROCHA, L. S (Org). Constituição, Sistemas Sociais e Hermenêutica. Porto Alegre: Livraria do Advogado, 2010, pp 289-308.

ENGELMANN, Wilson. As Nanotecnologias e a Gestão Transdisciplinar da Inovação. In: Wilson (Org.) As novas tecnologias e os Direitos Humanos: os desafios e as possibilidades para construir uma perspectiva transdisciplinar. Curitiba: Editora Honoris Causa, 2011, pp. 297-336.

ENGELMANN, Wilson. O diálogo entre as fontes do Direito e a gestão do risco empresarial gerado pelas nanotecnologias: construindo as bases à juridicização do risco. IN: STRECK, Lenio L.; ROCHA, Leonel S.; ENGELMANN, Wilson (Orgs). Constituição, Sistemas Sociais e Hermenêutica: anuário do Programa de Pós-Graduação em Direito da UNISINOS: Mestrado e Doutorado. Porto Alegre: Livraria do Advogado, 2012, n. 9, p. 319-344.

FEYNMAN, Richard P. There's Plenty of Room at the Bottom: an invitation to Enter a New Field of Physics. Palestra proferida em 29 de dezembro de 1959, por ocasião da Reunião Anual da Sociedade Americana de Física, no California Institute of Technology (CALTECH). 
Disponível em <http://www.zyvex.com/nanotech/feynman.html> Acesso em 10 de Setembro de 2018.

GARCÍA-PELAYO, Manuel. As transformações do Estado Contemporâneo. Rio de Janeiro: Forense, 2009.

HAWKEN, Paul. The Ecology of Commerce: a declaration of sustainability. New York: HarperCollins Publishers, 1993.

JUSTEN FILHO, Marçal. Curso de Direito Administrativo. 8. ed. Belo Horizonte: Fórum, 2012. LEITE, José Rubens Morato; AYALA, Patryck de Araújo. Direito ambiental na sociedade de risco. Rio de Janeiro: Forense Universitária, 2004.

LOPES, Marcel A; GALVÃO, Silvano M.; COSTA E SILVA, Tatiana M. Soberania Ambiental. In: XV Congresso Nacional do CONPEDI/UEA - Manaus, 2006, Manaus. Anais eletronicos do XV Congresso Nacional do CONPEDI/UEA - Manaus. Manaus: CONPEDI, 2006. Disponível em: <http://www.conpedi.org.br/anais_manaus.html>. Acesso em: 14 set. 2018.

LUHMANN, Niklas. Complejidad y modernidad: De la unidad a la diferencia. Madrid: Editorial Trotta.

LUHMANN, Niklas. El Derecho de la Sociedad. 2. ed. Cidade do México: Herder, 2005.

MACHADO, Paulo Affonso Leme. Direito Ambiental Brasileiro. 8 edição. São Paulo: Malheiros, 2000.

MATURANA, Humberto R.; VARELA, Francisco J. De máquinas e seres vivos: autopoiese - a organização do vivo. Porto Alegre: Artes Médicas, 1997.

MATURANA, Humberto; VARELA, Francisco. El arbol del conocimiento: Las bases biologicas del conocimiento humano. Madrid: Debate, 1996.

MODESTO, Paulo. O direito administrativo do terceiro setor: a aplicação do direito público às entidades privadas sem fins lucrativos. Revista de Direito da Procuradoria Geral: Rio de Janeiro. Rio de Janeiro, edição especial, p. 237-259, 2012.

MORAIS, José Luis Bolzan de. As crises do estado e da constituição e a transformação espaçotemporal dos direitos humanos. 2. ed. Porto Alegre: Livraria do Advogado, 2011.

MORIN, Edgar. Ciência com consciência. Rio de Janeiro: Bertrand Brasil, 2002.

NEVES, Marcelo. Transconstitucionalismo. São Paulo: Martins Fontes, 2009.

ROCHA, Leonel Severo; SCHWARTZ, Germano; CLAM, Jean. Introdução à Teoria do Sistema Autopoiético do Direito. Porto Alegre: Livraria do Advogado, 2005.

ROCHA, Leonel Severo. Epistemologia jurídica e democracia. São Leopoldo: UNISINOS, 1998. 
TEUBNER, Gunther. A Bukowina Global sobre a Emergência de um Pluralismo Jurídico Transnacional. Revista Impulso. Piracicaba, 14(33): 9-31, 2003.

TEUBNER, Gunther. Direito, sistema e policontexturalidade. São Paulo: UNIMEP, 2005.

TEUBNER, Gunther. O Direito como sistema autopoiético. Tradução de José Engracia Antunes. Lisboa: Fundação Calouste Gulbenkian, 1989.

TEUBNER, Gunther. The Corporate Codes of Multinationals: Company constitutions beyond corporate governance and co-determination. IN. NICKEL, Rainer (Ed.). Conflict of Laws and Laws of Conflict in Europe and beyond: patterns of supranational and transnational juridifaction. Hart: Oxford, 2009, pp. 261-275.

VIEIRA, Gustavo Oliveira. Inovações em Direito Internacional: um estudo de caso a partir do Tratado de Ottawa. Santa Cruz do Sul: EDUNISC, 2006.

WARAT, Luis Alberto. Saber crítico e senso comum teórico dos juristas. Revista Sequência. Florianópolis, v. 03, n. 05, p. 48-57, 1982. 